\title{
ANALISA KINERJA SIMPANG PASAR UNIT 2 KABUPATEN TULANG BAWANG PROPINSI LAMPUNG DENGAN METODE PEDOMAN KAPASITAS JALAN INDONESIA 2014
}

\author{
Leni Sriharyani ${ }^{1}$, Ida Hadijah ${ }^{2}$ \\ Prodi Teknik Sipil Universitas Muhammadiyah Metro, ${ }^{1,2}$ \\ E-mail : lenisriharyani8@gmail.com ${ }^{1}$,cv.sadakonsultan@yahoo.co.id ${ }^{2}$
}

\begin{abstract}
ABSTRAK
Simpang pasar unit 2 Tulang Bawang ini merupakan titik temu antara ruas jalan Lintas Sumatra, jalan Ethanol dan jalan Perintis. Aktifitas pasar, parkir di bahu jalan, pejalan kaki menyeberang dan menyusuri jalan serta hambatan samping jalan sangat mempengaruhi kelancaran arus lalu lintas yang melintasi simpang ini. Pada jam-jam tertentu terutama di pagi hari arus lalu lintas sangat tinggi terlebih ketika kegiatan pasar sudah mulai beraktivitas. Penelitian ini bertujuan untuk menganalisis kinerja. Parameter kinerja simpang yang dianalisis meliputi kapasitas, derajat kejenuhan, tundaan dan peluang antrian menggunakan pedoman PKJI 2014 (Pedoman Kapasitas Jalan Indonesia). Survei yang dilakukan dalam penelitian ini yaitu survei traffic counting (pencacah arus lalu lintas), survei hambatan samping, dan survei geometrik simpang. Dari hasil analisis diketahui bahwa kinerja simpang pasar Unit 2 Tulang Bawang pada volume tertinggi jam puncak sore derajat jenuh (DJ) 0,99 yang berarti bahwa pada kondisi eksisiting tersebut kinerja simpang adalah buruk. Alternatif untuk meningkatkan kinerja simpang adalah dengan melakukan 2 skenario. Alternatif 1 dilakukan pelebaran pada Jl. Perintis, lebar eksisting 5 meter menjadi 6 meter, didapatkan derajat kejenuhan (DJ) 0,96. Pada alternatif 2 dilakukan perancangan arus lalu lintas dengan memasang rambu kendaraan dilarang masuk atau forbidden ke Jl. Perintis dari arah Timur, jadi seluruh kendaraan yang akan melintas ke Jl. Perintis akan ada pengalihan arus kendaraan ke Jl. Seroja atau Jl. Melati didapatkan nilai derajat kejenuhan (DJ) 0,83. Dari nilai derajat kejenuhan alternatif tersebut, maka alternatif 2 dapat menjadi salah satu alternatif untuk perencanaan penanganan simpang dalam hal manajemen lalu lintas di lokasi penelitian.
\end{abstract}

Kata Kunci : Kapasitas Simpang, Derajat Kejenuhan, Tundaan.

\section{PENDAHULUAN}

Simpang pasar Unit 2 Kabupaten Tulang Bawang merupakan simpang dengan tipe 422, yakni memiliki empat lengan, dua lajur jalan minor dan dua lajur pada jalan utama. Simpang ini merupakan simpang tak bersinyal dan lokasinya berada pada daerah kawasan perdagangan, pertokoan (komersial), perkantoran, dan bisnis. Arus lalu lintas yang melewati simpang ini cukup tinggi mulai dari kendaraan berat, kendaraan ringan, kendaraan sedang, sepeda motor dan kendaraan tak bermotor. Simpang ini merupak titik temu antara ruas jalan Lintas Sumatra, jalan Ethanol dan jalan Perintis. Titik konflik yang terjadi pada simpang ini terlihat nyata antara kendaraan bermotor, kendaraan tidak bermotor maupun pejalan kaki. Pada jam-jam tertentu terutama di pagi hari aktifitas pemakai jalan sangat tinggi yaitu pada waktu aktifitas pasar melakukan kegiatan bongkar muat barang. Lampu tanda hati-hati pada simpang ini tidak 
berfungsi secara normal. Aktifitas pasar, parkir di bahu jalan, pejalan kaki menyeberang dan menyusuri jalan sangat mempengaruhi kelancaran arus lalu lintas yang melintasi simpang ini.

Begitupun hambatan samping yang terjadi di lokasi penelitian. Hambatan samping merupakan aktivitas samping jalan yang sering menimbulkan pengaruh yang cukup signifikan. Tingginya aktivitas samping jalan berpengaruh besar terhadap kapasitas dan kinerja jalan pada suatu wilayah perkotaan. Hambatan samping yang terjadi di lokasi penelitian ini sangatlah komplek diantaranya seperti pejalan kaki, penyeberang jalan, PKL (Pedagang Kaki Lima), Kendaraan berjalan lambat (becak, sepeda,), kendaraan berhenti sembarangan, parkir dibahu jalan (on street parking), dan kendaraan keluar-masuk pada aktivitas guna lahan sisi jalan. Salah satu penyebab tingginya aktivitas samping jalan yaitu disebabkan oleh perkembangan aktivitas penduduk yang setiap tahunnya tumbuh dan berkembang diwilayah perkotaan. Perkembangan aktivitas penduduk berpengaruh besar terhadap fasilitas dan pemenuhan kebutuhan namun hal tersebut belum diimbangi oleh penyediaan sarana dan prasarana transportasi yang memadai sehingga munculnya permasalahan transportasi pada ruas jalan perkotaan. Maka di perlukannya sarana dan prasarana transportasi di wilayah tersebut.

\section{TINJAUAN PUSTAKA}

\section{Tujuan Pengaturan Simpang}

Tujuan utama dari pengaturan lalu lintas umumnya adalah untuk menjaga keselamatan arus lalu lintas dengan memberikan petunjuk-petunjuk yang jelas dan terarah, tidak menimbulkan keraguan. Pengaturan lalu lintas di simpang dapat dicapai dengan menggunakan lampu lalu lintas, marka, dan rambu-rambu yang mengatur, mengarahkan, dan memperingati serta pulau-pulau lalu lintas (Ansyori, 2008)

Selanjutnya dari pemilihan pengaturan simpang dapat ditentukan tujuan yang ingin dicapai seperti berikut :

1. Mengurangi maupun menghindarikan kemungkinan terjadinya kecelakaan yang berasal dari berbagai titik konflik.

2. Menjaga kapasitas dari samping agar dalam operasinya dapat dicapai pemanfaatan simpang yang sesuai dengan rencana.

3. Dalam operasinya dari pengaturan simpang harus memberikan petunjuk yang jelas dan pasti serta sederhana, mengarahkan arus lalu lintas pada tempatnya yang sesuai.

Pada pengaturan persimpangan perlu memperhatikan arus lalu lintas baik dari jalan minor maupun dari jalan mayor, dari data arus tersebut dapat ditentukan tiga pengaturan di simpang yang meliputi:

1. Pengaturan dengan prioritas

a. Pengaturan simpang biasa

b. Pengaturan simpang dengan bundaran

2. Pengaturan dengan lampu lalu lintas

a. Pengaturan simpang biasa

b. Pengaturan simpang dengan bundaran

3. Pengaturan dengan simpang susun

Jenis-Jenis Pengaturan Simpang

Makin tinggi tingkat kompleksitas suatu simpang, makin tinggi pula kebutuhannya. Jenis pengaturan simpang sebidang dapat dikelompokkan menjadi:

1. Pengaturan simpang tanpa lampu lalu lintas

2. Pengaturan simpang dengan lampu lalu lintas

\section{Pengaturan Simpang Tanpa LAmpu Lalu Lintas}

Pengaturan simpang sebidang dapat dibedakan sebagai berikut:

1. Aturan Prioritas 
Ketentuan dari aturan lalu lintas pada simpang tanpa sinyal lalu lintas sangat mempengaruhi kelancaran pergerakan arus lalu lintas yang saling berpotongan terutama pada simpang yang merupakan perpotongan dari ruas-ruas jalan yang mempunyai kelas yang sama.

2. Rambu dan atau Marka

Rambu dan atau Marka, misalnya:

a. Rambu Yield

Pengaturan ini digunakan untuk melindungi arus lalu lintas dari salah satu ruas jalan pada dua ruas jalan yang saling berpotongan tanpa arus berhenti sama sekali. Sehingga pengendara tidak terlalu terhambat bila dibandingkan dengan pengaturan Stop Sign. Yield Sign juga digunakan pada simpang yang diatur dengan kanalisa yang digunakan untuk mengatur kendaraan belok kiri pada lajur percepatan terutama bila lajur percepatan tersebut kurang panjang.

b. Rambu Berhenti

Pengaturan simpang dengan Stop sign digunakan bila pengendara pada kaki simpang harus berhenti secara penuh sebelum memasuki simpang. Pengaturan digunakan pada pertemuan antara minor road dengan mayor road.

c. Kanalisa

Daerah perkerasan yang lebih luas, untuk melayani gerakan membelok pada kanal yang banyak, harus diberi tanda dengan tepat agar pengemudi dapat bergerak dengan mulus dan aman melalui pertemuan jalan. Sementara badan jalan diberi tanda panah dan garis untuk membantu manuver kendaraan, biasa diperlakukan pula pemisahan fisik dengan membangun pulau lalu lintas dan disediakan ruangan cadangan. Penerapan berbagai perangkat ini dikenal sebagai kanalisasi yang mempunyai maksud utama yaitu :
1) Pemisahan arus lalu lintas berdasar arah, gerakan kecepatan membeloknya.

2) Pemisahan tempat tunggu pejalan kaki terhadap arus lalu lintas dengan menyediakan "batu loncat" memotong arus kendaraan

3) Pengontrolan sudut pendekatan dan kecepatan kendaraan dengan mengarahkan arus sehingga memudahkan pengemudi dan memberikan kemudahan dalam pengoperasian kendaraan.

4) Pemisahan waktu dan jarak gerakan, terutama pada belokan yang kompleks membutuhkan penyederhanaan atau gerakan secra bertahap.

5) Pencegahan gerakan terlarang dengan menempatkan pulau lalu lintas pada jalur terlarang dengan menempatkan pulau lalu lintas pada jalur masuk atau keluar dari sebuah jalan.

Pulau lalu lintas juga berguna sebagai tempat untuk mendirikan alat kontrol dan rambu-rambu lalu lintas. Daerah badan jalan yang dialokasikan untuk fungsi tertentu dapat mempunyai permukaan jalan yang diberi warna atau tekstur yang berbeda. Perhatian yang besar harus diberikan sehingga penempatan pulau lalu lintas tidak mengganggu visibilitis atau membuat radius yang tidak cukup bagi berbagai kecepatan masuk dan kendaraan. Sinyal yang memadai termasuk pembuatan marka pada badan jalan, dibutuhkan untuk menghindari kebingungan, gangguan dan kerusakan pada perlengkapan suatu jalan. Tujuan utamanya adalah memberikan kebebasan kepada pengemudi untuk melakukan perpindahan yang lancar dari suatu arah kearah yang lain sesuai keputusannya dengan waktu dan ruang yang memadai.

d. Bundaran

Bundaran (Roundabout) dapat dianggap sebagai kasus istimewa dari kanalisasi yang pulau ditengahnya dapat bertindak sebagai pengontrol pembagi dan pengarah bagi system lalu lintas berputar satu arah. Pada cara ini Gerakan 
penyilangan hilang dan digantikan denga gerakan menyiap berpindah-pindah jalur. Dengan sebuah pulau lalu lintas berdiameter kurang dari 15 meter gerakan menyilang yang bukan tugak lurus akan dilakukan pada kecepatan relatif tinggi dan pada bundaran itu tidak menyediakan gerakan menyiap yang biasa lagi. Bundaran dengan diameter lebih besar dari 20 meter, jalur gerakan dan divergensi arus yang terletak pada titik keluar.

Dengan memperhitungkan jarak perjalanan nag lebih baik dan pengurangan kecepatan untuk masuk dari jalur pendekatan, jumlah total kelambatan kendaraan dan melebihi dari sebuah pertemuan jalan berkanalisasi. Tetapi Gerakan menerus dengan Gerakan membelok yang besar pada seluruh kaki pertemuan jalan akan mengurangi sumber kecelakaan dan memberikan kenyamanan yang lebih pada kondisi pengemudi, terutama pada lokasi pinggiran kota dengan volume sedang. Sinyal pada bundaran dapat menaikkan kapasitas tetapi sinyal itu sendiri mengurangi tujuan bundaran yaitu Gerakan menerus. Pertemuan jalan kanalisasi yang dikontrol dengan sinyal biasanya lebih disukai dan pekerjaan dapat dilakukan dalam beberapa tahap.

a. Lampu Lalu Lintas

Pengaturan simpang dengan lampu lalu lintas termasuk yang paling efektif terutama untuk volume lalu lintas pada kaki-kaki simpang yang relativ tinggi. Pengaturan ini dapat mengurangi atau menghilangkan titik-titik konflik pada simpang dengan memisahkan pergerakan arus lalu lintas pada waktu yang berbedabeda.

\section{Klasifikasi Jenis Kendaraan}

Klasifikasi Jenis Kendaraan menurut PKJI 2014 dapat dilihat pada Tabel 1 di bawah ini.

Tabel 1. Klasifikasi Jenis Kendaraan

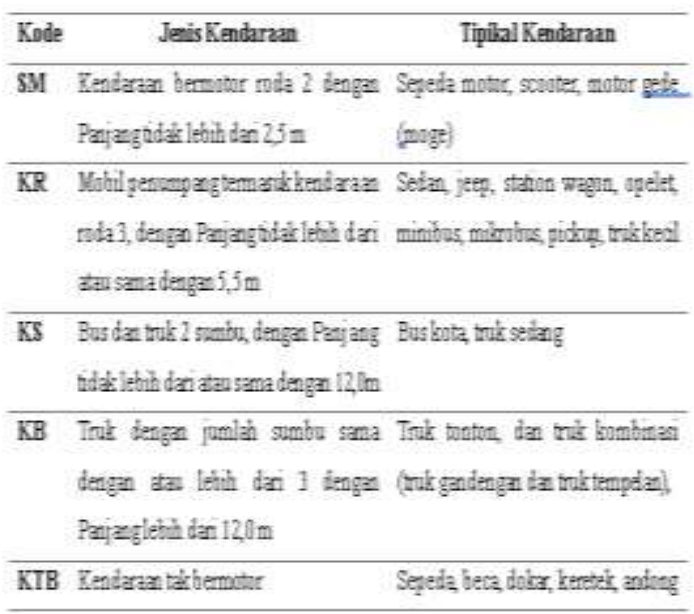

(PKJI, 2014)

\section{Kapasitas Simpang}

Kapasitas simpang dihitung untuk total arus yang masuk dari seluruh lengan simpang dan didefinisikan sebagai perkalian antara kapasitas dasar (Co) yaitu kapasitas pada kondisi ideal, dengan faktor-faktor koreksi yang memperhitungkan perbedaan kondisi lingkungan terhadap kondisi idealnya. Persamaan untuk menghitung kapasitas simpang adalah sebagai berikut (PKJI, 2014) :

$C=C_{O} \times F_{L P} \times F_{M} \times F_{U K} \times F_{H S} \times F_{B K i} \times$

$\mathbf{F}_{\text {BKa }} \times \mathbf{F}_{\text {Rmi }}$

Keterangan :

C : kapasitas Simpang, skr/jam

$\mathrm{C}_{\mathrm{O}}$ : kapasitas dasar Simpang, skr/jam

$F_{L P}$ : faktor koreksi lebar rata-rata pendekat

$\mathrm{F}_{\mathrm{M}}$ : faktor koreksi tipe median

$\mathrm{F}_{\mathrm{UK}}$ : faktor koreksi ukuran kota

$\mathrm{F}_{\mathrm{HS}}$ : faktor koreksi hambatan samping

$\mathrm{F}_{\mathrm{BKi}}$ : faktor koreksi rasio arus belok kiri

$\mathrm{F}_{\mathrm{BKa}}$ : faktor koreksi rasio arus belok kanan

$\mathrm{F}_{\mathrm{Rmi}}$ : faktor koreksi rasio arus dari jalan

Minor

\section{Kapasitas dasar Simpang, Co (skr/jam)}

Co ditetapkan secara empiris dari kondisi simpang yang ideal yaitu dengan lebar lajur pendekat rata-rata $2,75 \mathrm{~m}$, tidak ada median, ukuran kota 1-3 juta jiwa, hambatan samping sedang, rasio 
belok kiri 10\%, rasio belok kanan 10\%, rasio arus dari jalan minor $20 \%$, dan $\mathrm{qKTB}=0$. Nilai Co simpang ditunjukkan dalam Tabel 2.

Tabel 2. Kapasitas dasar Simpang-3 dan Simpang-4

\begin{tabular}{ll}
\hline Tipe Simpang & Co, skr/jam \\
\hline 322 & 2700 \\
\hline 324 atau 344 & 3200 \\
\hline 422 & 2900 \\
\hline 424 atau 444 & 3400 \\
\hline (PKJI, 2014) &
\end{tabular}

Faktor koreksi lebar rata-rata pendekat $\left(\mathbf{F}_{\mathrm{LP}}\right)$

Faktor koreksi lebar rata-rata pendekat $\left(\mathrm{F}_{\mathrm{LP}}\right)$ dapat dihitung dari persamaan di bawah ini :

Untuk tipe simpang 422:

$F_{L P}=0,70+0,0866 L_{R P}$

Untuk tipe simpang 424 atau 444

$F_{L P}=0,62+0,0740 L_{R P}$

Untuk tipe simpang 322

$F_{L P}=0,73+0,0760 L_{R P}$

Untuk tipe simpang 324 atau 344

$F_{L P}=0,62+0,0646 L_{R P}$

Faktor koreksi median, $\mathbf{F}_{M}$

Tabel 3. Faktor koreksi median, $F_{M}$

\begin{tabular}{lll}
\hline Kondisi Simpang & Tipe median & $\begin{array}{l}\text { Faktor } \\
\text { koreksi, F }\end{array}$ \\
\hline $\begin{array}{l}\text { Tidak ada median } \\
\text { di jalan mayor }\end{array}$ & Tidak ada & 1,00 \\
\hline $\begin{array}{l}\text { Ada median di } \\
\text { jalan mayor dengan }\end{array}$ & & \\
\hline $\begin{array}{l}\text { lebar }<3 \mathrm{~m} \text {. } \\
\text { Ada median di }\end{array}$ & Median lebar & 1,20 \\
jalan mayor dengan & & \\
lebar $\geq 3 \mathrm{~m}$ & &
\end{tabular}

(PKJI, 2014)

Median disebut lebar jika kendaraan ringan dapat berlindung dalam daerah median tanpa mengganggu arus lalu lintas, sehingga lebar median $\geq 3 \mathrm{~m}$. klasifikasi median berikut faktor koreksi median pada jalan mayor diperoleh dalam Tabel 3. koreksi median hanya digunakan untuk jalan mayor dengan 4 lajur.

Faktor koreksi ukuran kota, $\mathbf{F}_{\text {UK }}$

$\mathrm{F}_{\mathrm{UK}}$ dibedakan berdasarkan ukuran populasi penduduk. Nilai $F_{U K}$ dapat dilihat dalam Tabel 4.

Tabel 4. Faktor koreksi ukuran kota, $\mathrm{F}_{\mathrm{UK}}$

\begin{tabular}{lrr}
\hline $\begin{array}{l}\text { Ukuran } \\
\text { kota }\end{array}$ & $\begin{array}{c}\text { Populasi } \\
\text { penduduk, } \\
\text { juta jiwa }\end{array}$ & $\mathbf{F}_{\text {UK }}$ \\
\hline Sangat kecil & $\begin{array}{c}<0,1 \\
\text { Kecil }\end{array}$ & 0,82 \\
\hline Sedang & $0,1-0,5$ & 0,88 \\
\hline Besar & $0,5-1,0$ & 0,94 \\
\hline Sangat hesar & $1,0-3,0$ & 1,00 \\
\hline
\end{tabular}

(PKJI, 2014)

Faktor koreksi hambatan samping, $\mathbf{F}_{\mathrm{HS}}$

Pengaruh kondisi lingkungan jalan, hambatan samping, dan besarnya arus kendaraan fisik, kendaraan tak bermotor, akibat kegiatan disekitar simpang terhadap kapasitas dasar digabungkan menjadi satu nilai faktor koreksi hambatan samping $\left(\mathrm{F}_{\mathrm{HS}}\right)$. Nilai $\mathrm{F}_{\mathrm{HS}}$ dapat dilihat dalam Tabel 5. di bawah ini.

Tabel 5. $F_{H S}$ sebagai fungsi dari tipe lingkungan jalan, $\mathrm{HS}$, dan $\mathrm{R}_{\mathrm{KTB}}$

\begin{tabular}{|c|c|c|c|c|c|c|c|}
\hline \multirow{2}{*}{$\begin{array}{l}\text { Tpe } \\
\text { inghungan } \\
\text { jalan }\end{array}$} & \multirow{2}{*}{ HS } & \multicolumn{6}{|c|}{$\mathrm{F}_{\mathrm{ES}}$} \\
\hline & & $\mathrm{R}_{\mathrm{EM}} \mathrm{t}$ & 4,95 & t,11 & 0,15 & 1.2i & $\geq 0,25$ \\
\hline \multirow{3}{*}{ Konersial } & Ingy & 0.93 & 0.88 & 6,84 & 0,79 & 0,74 & 0,70 \\
\hline & Sedng & 0.94 & 0.89 & 0,85 & 0,80 & 0,75 & 0,70 \\
\hline & Rendah & 0.95 & 099 & 0.86 & 0,81 & 0,56 & 0,71 \\
\hline \multirow{3}{*}{ Permulimen } & Inggi & 0.95 & 0.91 & $0 ., 86$ & 0,12 & 0,57 & 0,72 \\
\hline & Seding & 0,97 & 0,92 & 0,87 & 0,82 & 0,37 & 0,73 \\
\hline & Rendah & 0.98 & 093 & 0.88 & 0,13 & 0,78 & 0,74 \\
\hline $\begin{array}{l}\text { Alses } \\
\text { Terbates }\end{array}$ & $\begin{array}{l}\text { Tnggi Sedang } \\
\text { Rendah }\end{array}$ & 1,109 & 095 & 6,90 & 0,85 & 0.89 & 0,75 \\
\hline
\end{tabular}

(PKJI, 2014)

Faktor koreksi rasio arus belok kiri, $\mathbf{F}_{\text {BKi }}$

$\mathrm{F}_{\mathrm{BKi}}$ dapat dihitung menggunakan persamaan untuk menghitung $\mathrm{F}_{\mathrm{BKi}}$ adalah sebagai berikut:

$F_{\mathrm{BKi}}=\mathbf{0 , 8 4}+\mathbf{1 , 6 1} \mathbf{R}_{\mathrm{BKi}}$

Keterangan : 
$\mathrm{R}_{\mathrm{BKi}}$ adalah rasio belok kiri

Faktor koreksi rasio arus belok kanan, $\mathbf{F}_{\text {BKa }}$

$F_{B K a}$ dapat diperoleh dengan menghitung menggunakan persamaan untuk menghitung $\mathrm{F}_{\mathrm{BKa}}$ adalah sebagai berikut:

Untuk Simpang-4:

$\mathrm{F}_{\text {BKa }}=\mathbf{1 , 0}$

Untuk Simpang-3:

$F_{\text {BKa }}=1,09-0,922 R_{\text {Bka }}$

Keterangan :

$\mathrm{R}_{\mathrm{BKa}}$ adalah rasio belok kanan

Faktor koreksi rasio arus dari jalan minor, $\mathbf{F}_{\text {Rmi }}$

$F_{m i}$ dapat ditentukan menggunakan persamaan-persamaan yang ditabelkan dalam Tabel 6. di bawah ini.

Tabel 6. Faktor koreksi rasio arus dari jalan minor, $\mathrm{F}_{\mathrm{Rmi}}$

\begin{tabular}{|c|c|c|}
\hline Tipe Sinpang & $F_{\mathbf{m i}}$ & $\mathbb{R}_{\mathrm{mi}}$ \\
\hline 422 & $1,19 \mathrm{x} \mathrm{R}_{\mathrm{ei}}^{2}-1,19 \mathrm{x} \mathrm{R}_{\mathrm{e}}+1,19$ & $0,1,1,9$ \\
\hline $424 \$ 44$ & 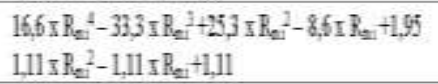 & $0,1,4,3$ \\
\hline 322 & 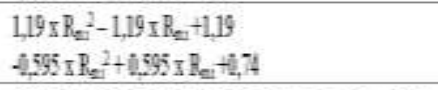 & $0,1,1,5$ \\
\hline $324 \& 34$ & 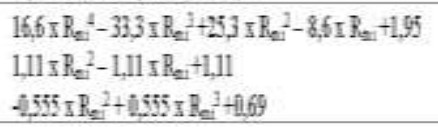 & $\begin{array}{l}0,1.1,3 \\
0,1,1,5 \\
0,5-1,9\end{array}$ \\
\hline
\end{tabular}

(PKJI, 2014)

\section{Derajat Kejenuhan}

Dj Simpang dihitung menggunakan persamaan

$\boldsymbol{D} \boldsymbol{j}=\frac{q}{c}$

Keterangan :

Dj adalah derajat kejenuhan

q adalah semua arus lalu lintas yang masuk Simpang dalam satuan skr/jam.

q dihitung menggunakan Rumus :

$\mathbf{q}=\mathbf{q}_{\text {kend }} \times \mathbf{F}_{\text {skr }}$

$F_{\text {skr }}$ adalah faktor skr yang dihitung

menggunakan persamaan :

$F_{\text {skr }}=\operatorname{ekrKR} x \% q K R+\operatorname{ekrKS} x$

$\% q K S+$ ekrSM x \%qSM

ekrKR, ekrKS, ekrSM masing-masing adalah ekr untuk KR, KS dan SM yang dapat diperoleh dari Tabel 7.
Tabel 7. Nilai ekivalen kendaraan ringan untuk KS dan SM

\begin{tabular}{|c|c|c|}
\hline \multirow{2}{*}{$\begin{array}{l}\text { Jenis } \\
\text { kendaraau }\end{array}$} & \multicolumn{2}{|c|}{ ekx } \\
\hline & $\begin{array}{l}\text { QTOTAL } \\
\geq 1000 \\
\text { sks/jam }\end{array}$ & $\begin{array}{l}\text { QTOTAL } \\
<1000 \\
\text { skrojam }\end{array}$ \\
\hline $\mathrm{KR}$ & 1,0 & 1,0 \\
\hline $\mathrm{KS}$ & 1,8 & 1,3 \\
\hline SM & 0,2 & 0,5 \\
\hline
\end{tabular}

(PKJI, 2014)

qKR, qKS, qSM masing-masing adalah q untuk KR, KS dan SM.

C adalah kapasitas simpang, skr/jam

\section{Tundaan}

Tundaan terjadi karena dua hal, yaitu tundaan lalu lintas (TLL) dan tundaan geometrik (TG). TLL adalah tundaan yang disebabkan oleh interaksi antara kendaraan dalam arus lalu lintas. Dibedakan TLL dari seluruh simpang, dari jalan mayor saja, atau jalan minor saja. TG adalah tundaan yang disebabkan oleh perlambatan dan percepatan yang terganggu saat kendaraan-kendaraan membelok pada suatu simpang dan/atau terhenti. $\mathrm{T}$ dihitung menggunakan persamaan berikut.

$$
\mathbf{T}=\mathbf{T L}+\mathbf{T G}
$$

TLL adalah tundaan lalu lintas ratarata untuk semua kendaraan bermotor yang masuk Simpang dari semua arah atau ditentukan dari kurva empiris sebagai fungsi dari DJ.

Untuk $\mathrm{DJ} \leq 0,60$ :

TLL $=2+8,2078$ DJ $-(1-D J)^{2}$

Untuk DJ>0,60:

$$
\text { TLL }=\frac{1,0504}{(0,2742-0,2042 D J)}-(1-D J)^{2}
$$

Tundaan lalu lintas untuk jalan mayor (TLLma) adalah tundaan lalu lintas rata-rata untuk semua kendaraan bermotor yang masuk Simpang dari jalan mayor, dapat dihitung menggunakan persamaan berikut.

Untuk $\mathrm{DJ} \leq 0,60$ : 
TLLma $=1,8000+5,8234 \mathrm{DJ}-$ $(1-D J)^{1,8}$

Untuk DJ>0,60:

$$
\begin{aligned}
& \text { TLLma }=\frac{1,0503}{(0,3460-0,2460 \text { DJ })}- \\
& (1-D J)^{1,8}
\end{aligned}
$$

Tundaan lalu lintas untuk jalan minor (TLLmi) adalah tundaan lalu lintas rata-rata untuk semua kendaraan bermotor yang masuk Simpang dari jalan minor, dapat dihitung menggunakan persamaan berikut

TLLmi $=\frac{\text { qTOT x TLL }- \text { qma } \times \text { TLLma }}{\text { qmi }}$

Keterangan :

qTOT: arus total yang masuk Simpang, skr/jam

qma : arus yang masuk Simpang dari jalan mayor, skr/jam

TG :Tundaan geometrik rata-rata seluruh simpang dapat diperkirakan penggunakan persamaan :

Untuk DJ $<1$ :

$\mathbf{T G}=(\mathbf{1}-\mathbf{D J}) \mathbf{x}\{\mathbf{6 R B}+\mathbf{3}(\mathbf{1}-\mathbf{R B})\}+$ 4DJ (detik/skr)

Untuk DJ $\geq 1$ :

$\mathbf{T G}=4 \mathrm{detik} / \mathbf{s k r}$

Keterangan:

TG Tundaan geometrik. detik/skr

DJ adalah Derajat kejenuhan

RB adalah Rasio arus belok terhadap arus total simpang

\section{Peluang Antrian}

PA dinyatakan dalam rentang kemungkinan (\%) dan dapat ditentukan menggunakan persamaan berikut.

Batas atas peluang:

$\mathrm{PA}=47,71 \mathrm{DJ}-24,68 \mathrm{DJ} \mathrm{J}^{2}+$

$56,47 \mathrm{DJ}^{3}$

Batas bawah peluang:

$\mathrm{PA}=9,02 \mathrm{DJ}+20,66 \mathrm{DJ}^{2}+$ $10,49 \mathrm{DJ}^{3}$

\section{Penilaian Kinerja}

Berdasarkan PKJI 2014, untuk penilaian kinerja lalu lintas operasional, gunakan nilai DJ sebagai ukuran utamanya. Jika nilai DJ yang masih jauh lebih kecil dari 0,85, maka Simpang tersebut masih dipandang layak untuk dioperasikan sampai beberapa tahun yang akan datang. Untuk penetapan lamanya pelayanan Simpang sampai nilai DJ mencapai 0,85 , perlu dilakukan analisis proyeksi lalu lintas. Mengikuti pedoman perencanaan lalu lintas yang berlaku.

Jika nilai DJ melampaui 0,85 , maka perlu dilakukan perubahan untuk meningkatkan pelayanan Simpang, meliputi utamanya penambahan lebar rata-rata pendekat atau manajemen lalu lintas yang lain yang memungkinkan arus lalu lintas yang masuk ke Simpang tersebut berkurang atau kombinasinya.

Untuk penilaian kinerja lalu lintas desain Simpang, DJ pun digunakan sebagai ukuran. DJ pada akhir usia pelayanan Simpang agar tetap dipertahankan tidak melampaui nilai 0,85 . Desain perlu diperbaiki untuk ditingkatkan kapasitasnya jika DJ $\geq 0,85$.

Nilai T dan PA tergantung dari nilai DJ. Nilai $T$ dapat digunakan untuk analisis biaya manfaat akibat kehilangan nilai waktu. Nilai PA dapat digunakan untuk mengevaluasi desain geometric terkait dengan panjang lajur khusus untuk lajur membelok agar antrian yang terbentuk tidak menghalangi arus lalu lintas pada lajur utama dan ketersediaan ruang untuk menampung kendaraan yang antri sehingga tidak menutupi pergerakan kendaraan-kendaraan pada simpang yang berdekatan.

\section{METODE PENELITIAN}

Langkah-langkah tahapan yang dilakukan dalam penelitian ini adalah sebagai berikut :

1. Melakukan observasi, pengamatan serta studi pendahuluan ke lokasi penelitian. Dari observasi ini dapat diketahui kejadian-kejadian serta permasalahan lalu lintas yang terjadi pada daerah studi. Mengamati kondisi 
simpang, serta aktivitas pasar mulai dari pagi hingga sore hari. Sebab dari kegiatan aktivitas pasar ini dapat menimbulkan permasalahan lalu lintas serta konflik kendaraan di jalan raya. Kemudian dilanjutkan dengan merumuskan permasalahan yang terjadi di simpang tersebut.

2. Mengumpulkan studi-studi pustaka serta literatur yang berhubungan dengan simpang tidak bersinyal. Sebab lokasi penelitian merupakan simpang tidak bersinyal. Yaitu simpang tanpa APILL (Alat Pemberi Isyarat Lampu Lalu Lintas).

3. Melakukan pengumpulan data, baik data primer maupun data sekunder yang mendukung penelitian. Sebelum melakukan pengambilan data (survey lapangan) terlebih dahulu melakukan kegiatan pra survey (survey pendahuluan). Memberikan pangarahan ke tim surveyor, yang meliputi cara kerja pengambilan data, pembagian tugas surveyor, dengan tujuan untuk memberikan arahan, bimbingan dan petunjuk kepada tim surveyor dalam melaksanakan tugasnya.

4. Melakukan tabulasi data yakni olah data lapangan. Data tersebut antara lain : data geometrik simpang, data volume lalu lintas, data hambatan samping.

5. Membuat rekapitulasi data.

6. Selanjutnya dilakukan analisis dan pembahasan dari data-data tersebut.

7. Memberikan kesimpulan dan masukan atas permasalahan yang terjadi di simpang pasar Unit 2 Tulang Bawang.

Rancangan penelitian yang dilakukan meliputi:

1. Survei Pendahuluan

Dari survei pendahuluan inilah akan didapatkan gambaran kondisi lingkungan dan karakter arus lalu lintas yang melewati simpang.

2. Persiapan survei
Persiapan survei meliputi kegiatan persiapan alat yang akan digunakan dalam survei dan persiapan tenaga surveyor yang akan dibutuhkan.

3. Pengarahan dan Pembekalan Surveyor

Pengarahan dan pembekalan kepada surveyor dilakukan dengan memberikan penjelasan cara kerja pengambilan data di lapangan. Hal ini dilakukan dengan tujuan untuk memudahkan surveyor dalam pengambilan data lapangan, maka sebelum pelaksanaan survey penelitian di lapangan dilaksanakan, surveyor diberikan penjelasan terlebih dahulu mengenai tugas dan tanggung jawab masing-masing. Antara lain yaitu dengan memberikan penjelasan mengenai cara pengisian formulir, pengklasifikasian jenis-jenis kendaraan, cara pengambilan data geometrik simpang dan cara pengambilan data hambatan samping.

4. Pelaksanaan Survei di lapangan

Pelaksanaan survei dilakukan setelah kegiatan persiapan dan penjelasan cara kerja telah dilakukan dengan matang. Dalam penelitian ini dilakukan beberapa macam survei yaitu survey geometrik simpang, survei volume lalu lintas, survei hambatan samping.

\section{HASIL PENELITIAN}

\section{Geometrik Simpang}

Simpang pasar Unit 2 Kabupaten Tulang Bawang merupakan simpang tidak bersinyal, terdiri dari empat lengan, simpang tersebut merupakan perpotongan antara ruas jalan Lintas Sumatra, jalan Perintis dan jalan Ethanol. Data geometrik simpang dapat dilihat dalam tabel 8. di bawah ini. 
Tabel 8. Data Geometrik Simpang Pasar Unit 2

\begin{tabular}{lccc}
\hline \multicolumn{1}{c}{ Nama Jalan } & $\begin{array}{c}\text { Lebar } \\
\text { Pendekat }(\mathrm{m})\end{array}$ & $\begin{array}{c}\text { Lebar } \\
\text { Trotoar }(\mathrm{m})\end{array}$ & Median \\
\hline JL. Lintas Sumatra (A) & 8.00 & 1.50 & Tidak Ada \\
JL. Perintis (B) & 5.00 & 1.50 & Tidak Ada \\
JL. Lintas Sumatra (C) & 8.00 & 1.50 & Tidak Ada \\
J. Ethanol (D) & 6.00 & 1.50 & Ada \\
\hline
\end{tabular}

(Sumber: Data Primer)

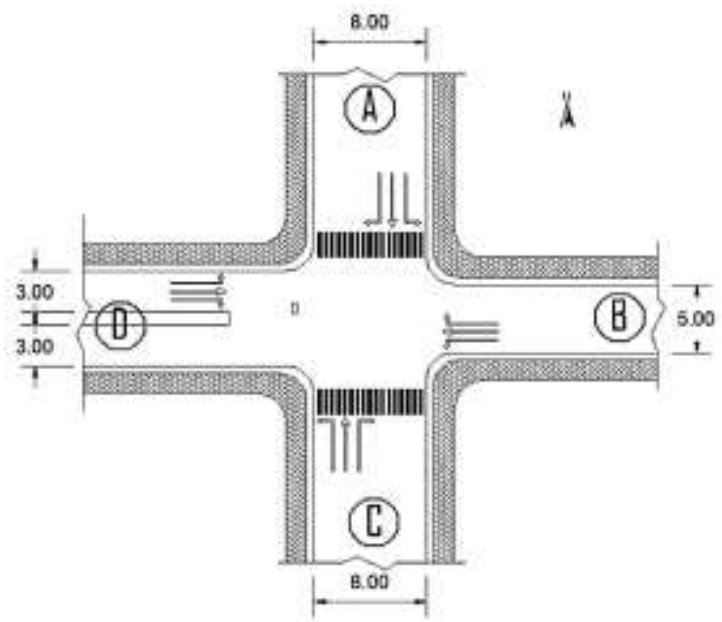

Gambar 1. Geometrik Simpang Pasar Unit 2

Dari tabel 8. dan Gambar 1. di atas dapat diketahui data geometrik simpang pasar Unit 2. Masing-masing lengan simpang memiliki kode yang berbedabeda, yaitu lengan A,B,C,D. Ruas jalan Lintas Sumatra memiliki kode lengan A,C. Ruas jalan Perintis dengan kode lengan $\mathrm{B}$, dan ruas jalan Ehanol memiliki kode lengan D. Setiap lengan memiliki pergerakan arus lalu lintas belok kiri, belok kanan dan lurus. Lengan A,B,C tidak memiliki median, hanya lengan $\mathrm{D}$ yakni jalan Ethanol yang memiliki median jalan.

\section{Volume Lalu Lintas}

Data volume lalu lintas didapatkan dari survey traffic counting. Survey dilakukan pada waktu jam puncak pagi pukul 06.00 hingga pukul 08.00, jam puncak siang pukul 11.00 hingga pukul 13.00, dan jam puncak sore pukul 16.00 hingga 18.00. Setiap jenis kendaraan yakni SM, KR, KS, KB dan KTB pada tiap lengan yang memasuki simpang yang melakukan pergerakan belok kiri, belok kanan dan lurus dicatat dengan interval waktu lima belas menit setiap jamnya. Selanjutnya data arus lalu lintas setiap jamnya akan dikonversikan menjadi skr (satuan kendaraan ringan) dengan cara mengalikan setiap jenis kendaraan dengan ekr (ekivalen kendaraan ringan) sesuai PKJI 2014. Data volume lalu lintas dapat dilihat pada Tabel 9. dibawah ini.

Tabel 9. Volume Lalu Lintas Simpang

\begin{tabular}{lc}
\hline Periode & $\begin{array}{c}\text { Arus Total,Q } \\
\text { skr/jam }\end{array}$ \\
\hline Pagi & 3868,20 \\
\hline Siang & 6353,95 \\
\hline Sore & 6820,00 \\
\hline
\end{tabular}

(Sumber: Hasil Analisis Data)

Dari tabel diatas dapat diketahui arus lalu lintas yang memasuki simpang pasar Unit 2 untuk tiga periode jam puncak yaitu jam puncak pagi, siang dan sore. Arus lalu lintas total tertinggi terjadi pada jam puncak sore sebesar 6820 skr/jam, dan terjadi pada hari Sabtu. Hal ini dapat dilihat dari observasi di lapangan, selain aktivitas kegiatan pasar, hari Sabtu menjadi hari menjelang akhir pekan. Dimungkinkan banyak terjadi pergerakan arus lalu lintas di akhir pekan, dengan tujuan yang beragam seperti jam pulang kantor, jam pulang dari tempat bekerja, berlibur, mengunjungi kerabat, atau pengiriman barang dari berbagi wilayah.

\section{Hambatan Samping}

Data hambatan samping didapatkan dari survey hambatan samping, yaitu dengan mencatat semua kegiatan samping jalan yang menghambat simpang. Hambatan samping tersebut meliputi: pejalan kaki, kendaraan berhenti dan parkir, kendaraan yang keluar masuk dari lahan samping jalan, kendaraan tidak bermotor yaitu kendaraan yang begerak lambat, seperti sepeda, becak, delman, pedati dan 
sejenisnya. Setiap tipe kejadian hambatan samping akan dikalikan dengan bobot hambatan samping sesuai ketentuan PKJI 2014. Sehingga dapat diketahui kriteria kelas hambatan samping yang terjadi di simpang. Data hambatan samping dapat dilihat dalam Tabel 10. di bawah ini.

Tabel 10. Hambatan Samping Simpang

\begin{tabular}{lc}
\hline Periode & $\begin{array}{c}\text { Bobot Total Kejadian } \\
\text { Hambatan Samping }\end{array}$ \\
\hline Pagi & $1.042,30$ \\
\hline Siang & 904,70 \\
\hline Sore & 891,40 \\
\hline
\end{tabular}

(Sumber: Hasil Analisis Data)

\section{Kapasitas Simpang Kondisi Eksisting}

Kondisi eksisting merupakan kondisi yang sesungguhnya atau kondisi yang sebenarnya terjadi pada saat pengambilan data di lapangan. Kondisi eksisting mencerminkan kondisi murni dan nyata yang terjadi, belum ada rekayasa ataupun alternatif penanganan. Analisis kapasitas simpang pasar Unit 2 Kabupaten Tulang Bawang diperoleh dengan cara mengalikan kapasitas dasar dengan berbagai factor koreksi kapasitas. Faktor koreksi yang berpengaruh terhadap kapasitas tersebut antara lain: lebar pendekat, median jalan, ukuran kota, hambatan samping, belok kiri, belok kanan, rasio minor. Nilai kapasitas simpang periode pagi, siang dan sore hari dapat dilihat pada tabel di bawah ini :

Tabel 11. Kapasitas Simpang Kondisi Eksisting

\begin{tabular}{ll}
\hline Periode & $\begin{array}{c}\text { Kapasitas } \\
\text { skr/jam }\end{array}$ \\
\hline Pagi & 4197,51 \\
\hline Siang & 6410,08 \\
\hline Sore & 6880,15 \\
\hline
\end{tabular}

(Sumber: Hasil Analisis Data)

Dari Tabel 11 di atas dapat diketahui bahwa kapasitas simpang kondisi eksisting untuk periode pagi, siang dan sore memiliki nilai yang berbeda-beda, tergantung dari factor koreksi yang mempengaruhinya. Dari kondisi eksisting tersebut, kapasitas simpang tertinggi terjadi pada sore hari sebesar 6880, 15 skr/jam.

\section{Kinerja Simpang Kondisi Eksisting}

Kinerja simpang merupakan ukuran kemampuan simpang dalam melayani arus lalu lintas dan pengguna jalan. Parameter ukuran kinerja simpang yang dianalisis dalam penelitian ini meliputi Derajat Kejenuhan (DJ), Tundaan (T), Peluang antrian (PA). Persamaan yang digunakan dalam analisis mengikuti PKJI 2014. Dari olah data yang dilakukan diperoleh kinerja simpang periode pagi, siang dan sore hari.

Tabel 12. Kinerja Simpang Kondisi Eksisting

\begin{tabular}{lccc}
\hline $\begin{array}{c}\text { Periode } \\
\text { Kejenuhan }\end{array}$ & $\begin{array}{c}\text { Derajat } \\
\text { Kundaan, T } \\
\text { (det/skr) }\end{array}$ & $\begin{array}{c}\text { Peluang } \\
\text { Antrian (\%) }\end{array}$ \\
\hline Pagi & 0,92 & 12,87 & $34,07-67,20$ \\
\hline Siang & 0,99 & 14,71 & $39,46-78,04$ \\
\hline Sore & 0,99 & 14,71 & $39,46-78,04$ \\
\hline
\end{tabular}

(Sumber: Hasil Analisis Data)

Dari Tabel 12. di atas dapat diketahui nilai derajat kejenuhan simpang tertinggi dengan nilai 0,99 . Nilai ini melebihi standar yang telah ditetapkan oleh PKJI 2014, dimana PKJI menetapkan nilai DJ adalah $\leq 0,85$. Derajat kejenuhan 0,99 berarti bahwa simpang pasar Unit 2 Kabupaten Tulang Bawang, dalam kondisi eksisting kinerjanya adalah buruk. Kinerja ini diperoleh berdasarkan data volume lalu lintas tertinggi yang terjadi di simpang tersebut. Dari analisis ini berarti bahwa simpang pasar Unit 2 Kabupaten Tulang Bawang membutuhkan penanganan dan rekayasa simpang supaya simpang kinerjanya menjadi lebih baik. Pertumbuhan lalu lintas semakin bertambah setiap tahunnya, tetapi belum 
tentu simpang mengalami perubahan desain geometrik maupun rekayasa lalu lintas yang kontinu setiap tahunnya. Lambat laun arus lalu lalu yang memasuki simpang akan melebihi kapasitas simpang, sehingga akan terjadi kemacetan. Terlebih pada simpang yang tidak ada APILL nya, selain menimbulkan kemacetan jelas titik konflik pada simpang akan semakin bertambah.

\section{Kondisi Alternatif Perencanaan}

Berdasarkan nilai derajat kejenuhan kondisi eksisting yang didapat yakni 0,99 maka diperlukan rekayasa penanganan perencanaan simpang dengan beberapa alternatif, supaya nilai derajat kejenuhan (DJ) bisa $\leq 0,85$. Hal ini dilakukan untuk meningkatkan kinerja simpang dan meningkatkan pelayanan simpang. Sehingga dari kinerja simpang yang buruk dapat ditingkatkan menjadi kinerja simpang yang baik.

Dalam penelitian ini dilakukan rekayasa penanganan perencanaan simpang dengan dua alternatif yakni :

a. Alternatif 1, melakukan rekayasa perancangan arus lalu lintas dengan melakukan pelebaran pada Jl. Perintis, yang semula lebar existing nya 5 meter menjadi 6 meter.

b. Alternatif 2, melakukan rekayasa perancangan arus lalu lintas dengan memasang rambu kendaraan dilarang masuk atau forbidden ke Jl. Perintis dari arah Timur, jadi seluruh kendaraan yang akan melintas ke Jl. Perintis akan ada pengalihan arus kendaraan ke Jl. Seroja atau Jl. Melati. Analisis Kondisi Alternatif Perencanaan dilakukan dengan menghitung kapasitas (C), derajat kejenuhan (DJ), tundaan (T) dan peluang antrian (PA) dengan berpedoman pada PKJI 2014. Rekapitulasi nilai kinerja simpang kondisi alternatif perencanaan dapat dilihat dalam Tabel 13. dan Tabel 14. di bawah ini.
Tabel 13. Arus Total dan Kapasitas Simpang Kondisi Alternatif Perencanaan Penanganan

\begin{tabular}{clcc}
\hline Kondisi & Periode & $\begin{array}{c}\text { Arus } \\
\text { Total,Q } \\
\text { skr/jam }\end{array}$ & $\begin{array}{c}\text { Kapasitas } \\
\text { skr/jam }\end{array}$ \\
\hline \multirow{3}{*}{ Alternatif 1 } & Sagi & 3868,20 & 4352,98 \\
& Siang & 6353,95 & 6647,49 \\
& Sore & 6820,00 & 7134,97 \\
\hline \multirow{3}{*}{ Alternatif 2 } & Pagi & 3868,20 & 4269,96 \\
& Siang & 4718,70 & 5926,70 \\
& Sore & 5289,60 & 6383,59 \\
\hline
\end{tabular}

(Sumber: Hasil Analisis Data)

Tabel 14. Kinerja Simpang Kondisi Alternatif Perencanaan Penanganan

\begin{tabular}{|c|c|c|c|c|}
\hline Kondisi & Pealode & $\begin{array}{l}\text { Derajat } \\
\text { Krianuhan }\end{array}$ & $\begin{array}{l}\text { Tundasn T } \\
\text { (det } 4 \text { tr) }\end{array}$ & $\frac{\frac{\text { Poduan: }}{\text { Antrian }}}{(S)}$ \\
\hline \multirow{3}{*}{ Alternatif 1} & Pagi & 0,89 & 12,24 & $31,69.62,53$ \\
\hline & Sing & 0,96 & 13,67 & $36,66-72,37$ \\
\hline & Sort & 096 & 13.68 & $36,66-72,37$ \\
\hline \multirow{3}{*}{ Alternatif 2} & Pagi & 0,79 & 10,89 & $25,00-49,77$ \\
\hline & Sing & 0.90 & 10,98 & $25,57.50 .84$ \\
\hline & Sore & 0.83 & 11.26 & $27,63 \cdot 54,72$ \\
\hline
\end{tabular}

(Sumber: Hasil Analisis Data)

Berdasarkan Tabel 14. untuk alternatif 1 periode sore hari diperoleh nilai DJ 0,96. Nilai DJ pada alternatif 1 ini masih melebihi ketentuan yakni DJ $\leq$ 0,85 . Pada alternatif 2 periode sore hari nilai derajat kejenuhan (DJ) 0,83 . Nilai ini sudah sesuai dengan standar yaitu DJ $\leq 0,85$. Dari kedua alternatif yang dilakukan, alternatif 2 DJ nya lebih baik dibandingkan dengan DJ alternatif 1 . Maka alternatif 2 dapat digunakan sebagai salah satu alternatif untuk perencanaan penanganan simpang dalam hal manajemen lalu lintas di lokasi penelitian.

\section{KESIMPULAN}

Dari hasil analisis yang dilakukan dapat disimpulkan bahwa :

1. Kinerja simpang pasar Unit 2 Kabupaten Tulang Bawang dalam kondisi eksisting berdasarkan arus lalu 
lintas tertinggi pada periode sore hari dengan nilai kapasitas (C) 6880,45 skr/jam, arus total (Q) 6820,00 skr/Jam, derajat kejenuhan (DJ) 0,99, tundaan simpang (T) 14,71 detik/skr, dan peluang antrian $39,46 \%$ sampai dengan $78,04 \%$.

2. Alternatif perencanaan untuk meningkatkan kinerja pada simpang pasar Unit 2 Kabupaten Tulang Bawang dilakukan dengan rekayasa perancangan arus lalu lintas dengan memasang rambu kendaraan dilarang masuk atau forbidden ke Jl. Perintis dari arah Timur, jadi seluruh kendaraan yang akan melintas ke $\mathrm{Jl}$. Perintis yang akan memasuki simpang, akan ada pengalihan arus kendaraan ke Jl. Seroja atau Jl. Melati.

\section{DAFTAR PUSTAKA}

Ansyori Alik Alamsyah (2008), Rekayasa Lalu Lintas, Edisi Revisi, UMM Press, Malang.

Daryl Muhammad dan Elkhasnet (2019), Analisis Kinerja Simpang Tak Bersinyal Jalan A.H. Nasution danJalan Cikadut, Kota Bandung, RekaRacana: Jurnal Teknik Sipil, No. 2, Vol. 5, Juni.

Departemen Pekerjaan Umum (1997), Manual Kapasitas Jalan Indonesia, Direktorat Jendral Bina Marga, Jakarta.

Departemen Pekerjaan Umum (2014), Pedoman Kapasitas Jalan Indonesia, Direktorat Jendral Bina Marga, Jakarta.

Esti Dwi Intari dkk (2019), ANALISIS KINERJA SIMPANG TIGA TAK BERSINYAL (Studi Kasus : Simpang Tiga Jalan Raya Serang Km 24 - Jalan Akses Tol Balaraja Barat, Balaraja, Kabupaten Tangerang, Banten), Jurnal Fondasi, Volume 8 No.1.
Khilmi Moch dan Kurnia Hadi (2021), Evaluasi Kinerja Simpang Tiga Tak Bersinyal Pada Jalan Raya Menganti - Jalan Mastrip Kota Surabaya, Seminar Teknologi Perencanaan, Perancangan, Lingkungan, dan Infrastruktur II, FTSP ITATS, 20 Februari.

Kurniawan, S. (2016). Analisis Hambatan Samping Akibat Aktivitas Perdagangan Modern (Studi Kasus: Pada Jalan Brigjen Katamso di Bandar Lampung). TAPAK (Teknologi Aplikasi Konstruksi): Jurnal Program Studi Teknik Sipil, 5(1).

Listiana Novi dan Tri Sudibyo (2018), Analsis Kinerja Simpang Tak Bersinyal Jalan Raya DramagaBubulak Bogor, Jawa Barat. JSIL, Jurnal Teknik Sipil dan Lingkungan, Vol.04 No,01, April.

Mahendra dkk (2013), Analisis Kinerja Simpang Tak Bersinyal Dan Ruas Jalan Di Kota Denpasar (Studi Kasus : Simpang Tak Bersinyal Jl. Gatot Subroto - J1. Mulawarman - Jl. Mataram Dan Simpang Tak Bersinyal Jl. Ahmad Yani - Jl. Mulawarman). Jurnal Ilmiah Teknik Sipil Vol.17 No.2 Juli.

Sriharyani Leni dan Ida Hadijah (2016), Analisis Kinerja Simpang Tidak Bersinyal (Studi Kasus Persimpangan Jalan, Ruas Jalan Jend. Sudirman, Jalan Sumbawa, Jalan Wijaya Kusuma dan Jalan Inspeksi). Jurnal TAPAK dengan ISSN No. 2089-2098, Vol. 6, No. 1 , November.

Waris Milawaty (2018), Analisis Kinerja Simpang Tak Bersinyal Metode Pedoman Kapasitas Jalan Indonesia 2014. J-HEST, Volume 1 Nomor 1 Desember. 